\title{
Effects of Filler Type and Content on the Mechanical, Morphological, and Thermal Properties of Waste Casting Polyamide 6 (W-PA6G)-based Wood Plastic Composites
}

\author{
Belgin Şeker Hirçin, ${ }^{a}, *$ Hüseyin Yörür, ${ }^{a}$ and Fatih Mengeloğlu ${ }^{\text {b,c }}$
}

\begin{abstract}
Cast polyamide 6 (PA6G), trade name Castamide, is a semi-crystalline polymer widely used in the engineering plastics industry. There is a need to recycle valuable waste (W)-PA6G generated during part manufacturing of this polymer (approximately $30 \%$ ). This study attempts to utilize WPA6G in the manufacture of wood-plastic composites as a polymeric matrix. The effect of lignocellulosic filler type (FT) and filler content (FC) on the mechanical, morphological, and thermal properties of W-PA6Gbased composites were investigated. During manufacturing, N-butyl benzene sulfonamide (N-BBSA) and lithium chloride ( $\mathrm{LiCl}$ ) were utilized as a plasticizer and a melt temperature-lowering salt, respectively. The rice husk $(\mathrm{RH})$ and Uludağ fir wood flour (WF) filled W-PA6G-based composites were successfully manufactured using a combination of extrusion and injection molding. Compared to $\mathrm{RH}$ filled composites, WF filled composites provided better tensile and flexural properties (both strength and modulus) at $20 \%$ and $30 \%$ filler contents. Morphological study showed the nonhomogeneous distribution of fillers in the polymeric matrix. Lignocellulosic filler resulted in reduced melting temperature and crystallinity of W-PA6G-based composites. This reduction was more pronounced in $\mathrm{RH}$ filled composites.
\end{abstract}

Keywords: Cast polyamide 6; Composite; Mechanical; Thermal; Morphological

Contact information: a: Department of Forest Industry Engineering, Karabük University, Karabuk, Turkey; b: Kahramanmaras Sutcu Imam University, Faculty of Forestry, Forest Industry Engineering, Kahramanmaras, Turkey; c: Department of Materials Science and Engineering, Graduate School of Natural and Applied Sciences, Kahramanmaras Sutcu Imam University, Kahramanmaras, Turkey;

* Corresponding author: belginseker@karabuk.edu.tr

\section{INTRODUCTION}

In recent years, the application of lignocellulosic material filled thermoplastic composites, or wood-plastic composites (WPCs), has increased in numerous areas such as wall coverings, floor coverings, balustrades, window profiles, docks, door frames, furniture, boat hulls, pallets, façade coverings, architectural profiles, and automotive parts (Lei and Wu 2010; Xu et al. 2018; Kabakci and Kesik 2020). Compared to unfilled ones, lignocellulosic material filled thermoplastics have increased bending strength, stiffness, high elasticity (both flexural and tensile modulus), low thermal expansion, and low cost (Lei and $\mathrm{Wu} 2010$ ). Extensive research has been conducted to assess the utilization of commodity thermoplastic, such as polyethylene (Mengeloglu et al. 2007; Adhikary et al. 2008; Çavdar et al. 2019), polypropylene (Espert et al. 2004; Mengeloglu et al. 2007), polyvinyl chloride (Jiang and Kamdem 2004), and polystyrene (PS) (Poletto et al. 2011) in WPC manufacturing. Addition of wood fibers has been found to enhance the mechanical properties of the commodity polymers, but their mechanical properties might not be enough 
for most engineering applications (Gardner et al. 2015). This directed attention to WPC produced from engineering thermoplastics in the last decade is due to their superior properties (excellent chemical resistance, high thermal stability, and high tensile, bending, and impact strengths) (Kiziltas et al. 2014). Several studies have been conducted in an attempt to produce WPCs with engineering thermoplastics. Yörür et al. (2013) reported that mechanical properties were improved due to the decrease in thickness swelling values with the increase of PA6G in wood composites. Chen and Gardner (2008) produced WPCs utilizing PA66 as a polymer matrix and reported composites with improved storage modulus, thermal stability, and reduced glass transition temperature. In some studies, engineering plastics are incorporated into general-purpose plastics to form polymer blends. In a two-step extrusion process, Lei and Wu (2010) produced wood flour filled polyethylene terephthalate (PET)/high-density polyethylene (HDPE) composites. In the first step, polymer blends were extruded at high temperature (allowing PET to melt). In the second step, wood flour was added into the previous polymer mixture (pellets) at low temperature to be extruded (allowing only HDPE to melt). Increased mechanical properties, storage modulus, and matrix crystallinity with wood flour addition were reported. Similarly, Liu et al. (2009) produced HDPE/Nylon 6/Banana fiber composites using various compatibilizers.

Cast polyamide 6 (PA6G) is one of the most widely used thermoplastics in the engineering plastic industry (Bozdemir 2011; Yörür and Şeker 2019). During production of PA6G parts, approximately $30 \%$ wastes are generated and can annually sum up to 5,000 tons in the European Union (Formisano et al. 2016; Formisano and Bonten 2019). Waste (W)-PA6G, a component of global solid wastes, is a promising raw material for WPCs due to its large volume and low cost. The PA6G has excellent mechanical properties with a melting temperature $\left(T_{\mathrm{m}}\right)$ higher than $200{ }^{\circ} \mathrm{C}$. Because wood filler starts decomposing around approximately $200{ }^{\circ} \mathrm{C}$, high $T_{\mathrm{m}}$ of polymers limits their utilization in WPC manufacturing (Sears et al. 2001; Lei and Wu 2010; Zierdt et al. 2015; Zierdt et al. 2016; $\mathrm{Xu}$ et al. 2018). It was reported that lithium chloride (LiCI), a halogenic salt, can remarkably reduce the melting temperature of polyamide 6 (PA6) (Amintowlieh et al. 2012; Xu et al. 2018). Recently, Yörür and Şeker (2019) reported that with the utilization LiCI and N-butyl benzene sulfonamide (N-BBSA) as an additive, melting temperatures of W-PA6G and W-PA6G composites were reduced approximately $3.6 \%$ and $7.2 \%$, respectively. The mechanical, thermal, and morphology of properties of waste-cast polyamide 6 (W-PA6G)-based WPCs are not reported in the literature. The aim of this study was to investigate the effect of filler type (FT: rice husk $[\mathrm{RH}]$ and fir wood flour [WF]) and filler content (FC: 0, 10, 20, and 30\%) on the mechanical, morphological, and thermal properties of W-PA6G-based composites.

\section{EXPERIMENTAL}

\section{Materials}

Rice husk (RH) and Uludağ fir (Abies bornmülleriana (Mattf.)) wood flour (WF) were used as fillers. The RH (density 0.90 to $0.150 \mathrm{~g} / \mathrm{cm}^{3}$ ) was provided by a paddy factory (Karabük, Turkey). Uludağ fir wood chips were supplied by a timber factory in Karabük, Turkey. Waste cast polyamide 6 was kindly donated by Plamek Plastic Industry and Commerce Plant (Bursa, Turkey). N-butyl benzene sulfonamide (N-BBSA) was purchased from Sigma Aldrich (St. Louis, MO, USA) as a plasticizer (density of $1.15 \mathrm{~g} / \mathrm{mL}$ and 
molecular weight of $213.30 \mathrm{~g} / \mathrm{mol}$ at $25{ }^{\circ} \mathrm{C}$ ). Lithium chloride ( $\left.\mathrm{LiCl}\right)$ salt (purity of $99 \%$, weight of $42.39 \mathrm{~g} / \mathrm{mol}$ and density of $2.068 \mathrm{~g} / \mathrm{cm}^{3}$ at $20{ }^{\circ} \mathrm{C}$ ) was used to lower the melting temperature of W-PA6G (Carlo Erba 2018). Mold release agent with $31 \%$ boron nitride (BN) was used (Alfa Aesar 2019).

\section{Methods}

The rice husk particles (RH) and Uludağ fir wood (WF) were turned into flour form using a Wiley mill (Altundal, Kahramanmaraş, Turkey) and further classified. Particles that passed through a 40 -mesh $(400 \mu \mathrm{m})$ screen and that stayed on a 60 -mesh $(250 \mu \mathrm{m})$ screen were used in this study. Then, the classified lignocellulosic filler materials and WPA6G were dried for $24 \mathrm{~h}$ at a temperature of $103 \pm 2{ }^{\circ} \mathrm{C}$ in an oven.

The W-PA6G-based composites were manufactured based on the manufacturing recipe presented in Table 1 . All ingredients were homogeneously mixed in a high intensity mixer (900 to $1000 \mathrm{rpm}$ in $2 \mathrm{~min}$ ). Mixtures were fed into a single screw extruder (TTB 30, Teknomatik, Istanbul, Turkey) with five heating zones. The extruder screw speed was set as $50 \mathrm{rpm}$ and the temperature ranged from 230 to $250{ }^{\circ} \mathrm{C}$ from barrel to die

Table 1. Production Recipe of W-PA6G Added WPCs

\begin{tabular}{|c|c|c|c|c|}
\hline ID & Filler (\%) & W-PA6G (\%) & LiCl (\%) & N-BBSA (\%) \\
\hline W-PA6G & - & 96.0 & 2 & 2 \\
\hline PA-10RH & 10 & 86.0 & 2 & 2 \\
\hline PA-20RH & 20 & 76.0 & 2 & 2 \\
\hline PA-30RH & 30 & 66.0 & 2 & 2 \\
\hline PA-10WF & 10 & 86.0 & 2 & 2 \\
\hline PA-20WF & 20 & 76.0 & 2 & 2 \\
\hline PA-30WF & 30 & 66.0 & 2 & 2 \\
\hline
\end{tabular}

The extruded compounds were first cooled in a water pool $\left(23 \pm 2{ }^{\circ} \mathrm{C}\right)$ and were granulated into pellets using a Wiley mill. The pellets were dried at $103 \pm 2{ }^{\circ} \mathrm{C}$ in an oven $(24 \mathrm{~h})$ to reduce moisture content below $1 \%$ before the injection molding using HAIDA HDX-88 (Haida Plastic Machinery Co., Ltd., Ningbo, China). Injection pressure and temperatures (from feed zone to die zone) were set as 5 to $6 \mathrm{MPa}$ and 190 to $220{ }^{\circ} \mathrm{C}$, respectively. Before testing, the specimens were conditioned in a climate cabinet at $23 \pm 2$ ${ }^{\circ} \mathrm{C}$ and $65 \pm 2 \%$ relative humidity. Tensile, flexural, and (notched) impact strength (IS) properties were determined based on the procedures of ASTM D638 (2001), ASTM D790 (2003), and ASTM D256 (2000), respectively, and at least five samples from each composition were tested. Tensile and flexural property tests were implemented on a Zwick $10 \mathrm{KN}$ (Zwick/Roell, Ulm, Germany), while a HIT5, 5P (Zwick) was used for IS testing on notched specimens. The notch was added using a RayRan ${ }^{\mathrm{TM}}$ Polytest notching cutter (London, UK).

The morphological properties of the fractured surfaces were studied using scanning electron microscopy (SEM) (EVO LS10; Carl Zeiss, Jena, Germany). All samples were plated with gold before microscopic observations (Sputter Coater 108 Auto; Cressington, London, England). The differential scanning calorimeter (DSC) analysis was performed on a HITACHI-DSC-STA7300 machine (Hitachi, Tokyo, Japonya ) using a heating rate of 10 ${ }^{\circ} \mathrm{C} / \mathrm{min}$ under nitrogen atmosphere from room temperature to $300{ }^{\circ} \mathrm{C}$. Thermo-gravimetric analysis (TGA) of the test samples was performed on the HITACHI-TGA-STA7300 
machine using a heating rate of $10{ }^{\circ} \mathrm{C} / \mathrm{min}$ under nitrogen atmosphere from room temperature to $800{ }^{\circ} \mathrm{C}$. For statistical analysis, the statistical software Design-Expert ${ }^{\circledR}$, version 7.0.3 (Stat-Ease Inc., Minneapolis, MN, USA) was used.

\section{RESULTS AND DISCUSSION}

\section{Mechanical Properties}

The effect of filler type (FT) and filler content (FC) on tensile properties (tensile strength (TS), tensile modulus (TM), and elongation at break (EatB)), flexural properties (flexural strength (FS), flexural modulus (FM)), and IS of W-PA6G-based composites were determined at room temperature. The mean values of measured mechanical properties are reported in Table 2.

Table 2. Mechanical Properties of W-PA6G-based Wood-plastic Composites

\begin{tabular}{|c|c|c|c|c|c|c|}
\hline ID & TS (MPa) & TM (MPa) & EatB (\%) & FS (MPa) & FM (MPa) & IS (kJ/m² \\
\hline \multirow{2}{*}{ W-PA6G } & 65.2 & 709 & 182 & 63.5 & 1237 & 18.7 \\
& $(2.46)$ & $(58)$ & $(6.7)$ & $(2.7)$ & $(58)$ & $(8.3)$ \\
\hline \multirow{2}{*}{ PA-10RH } & 62.4 & 931 & 8.5 & 72.0 & 1482 & 3.1 \\
& $(3.3)$ & $(46)$ & $(2.4)$ & $(12)$ & $(114)$ & $(0.7)$ \\
\hline \multirow{2}{*}{ PA-20RH } & 30.1 & 893 & 3.80 & 63.6 & 1529 & 1.9 \\
& $(1.5)$ & $(24)$ & $(0.2)$ & $(5.5)$ & $(155)$ & $(0.3)$ \\
\hline \multirow{2}{*}{ PA-30RH } & 25.7 & 674 & 4.8 & 40.4 & 965 & 1.3 \\
& $(3.7)$ & $(116)$ & $(0.3)$ & $(1.8)$ & $(40)$ & $(0.3)$ \\
\hline \multirow{2}{*}{ PA-10WF } & 38.0 & 819 & 4.9 & 54.2 & 1569 & 10.2 \\
& $(13.0)$ & $(81)$ & $(0.5)$ & $(13.0)$ & $(101)$ & $(6.1)$ \\
\hline \multirow{2}{*}{ PA-20WF } & 42.9 & 1036 & 4.2 & 77.3 & 2189 & 2.7 \\
& $(2.6)$ & $(42.2)$ & $(0.3)$ & $(5.5)$ & $(494)$ & $(1.6)$ \\
\hline \multirow{2}{*}{ PA-30WF } & 38.5 & 1039 & 3.6 & 63.7 & 2472 & 3.3 \\
& $(3.2)$ & $(80.7)$ & $(0.3)$ & $(6.6)$ & $(161)$ & $(3.3)$ \\
\hline
\end{tabular}

${ }^{*}$ : Values in parentheses are standard deviation

ANOVA table and interaction graphs of the tensile properties are resented in Table 3 and Fig. 1a, respectively. TS values of W-PA6G and W-PA6G-based composites were in the range from 25.7 to $65.2 \mathrm{MPa}$. The statistical analysis showed that lignocellulosic filler type did not have a significant effect on TS $(\mathrm{P}=0.8663)$. However, filler content had a significant effect on TS (P < 0.0001). Both the RH and WF fillers reduced the TS of WPA6G-based composites, and this reduction was affected by filler. The WF filled WPA6G-based composites provided better tensile and flexural properties (both strength and modulus) than the RH filled ones at $20 \%$ and $30 \%$ filler contents. Elsabbagh et al. (2017) produced PA6 composites using kenaf and flax as lignocellulosic fillers. It was reported that the addition of filler reduced TS values, and increased filler. The WF filled W-PA6Gbased composites provided better tensile and flexural properties (both strength and modulus) than the RH filled ones at $20 \%$ and $30 \%$ filler contents, which was caused additional property reduction in composites. Reduced TS values in beech fiber filled PA6and PA11-based composites were also reported by Zierdt et al. (2016). Similar results for various thermoplastic composites filled with lignocellulosic material were reported by others (Xu 2008; Malkapuram et al. 2009; Ku et al. 2011). Significant effect of two factors' interaction (FTxFC) suggested that the influence of filler content was not the same and 
showed some variety among filler types. For this study, RH filler performed better at low filler content $(10 \%)$ but WF outperformed it at higher filler contents.

Table 3. Analysis of Variance (ANOVA) Table of Tensile Strength

\begin{tabular}{|c|c|c|c|c|c|}
\hline Source & $\begin{array}{c}\text { Sum of } \\
\text { Squares }\end{array}$ & df & Mean Square & F-Value & $\begin{array}{c}\mathbf{p} \text {-value } \\
\text { Prob }>\text { F }\end{array}$ \\
\hline Model & 9023.66 & 7 & 1289.09 & 46.17 & $<0.0001$ \\
\hline A-Filler Type & 0.80 & 1 & 0.80 & 0.029 & 0.8663 \\
\hline B-Filler Content (\%) & 6708.36 & 3 & 2236.12 & 80.09 & $<0.0001$ \\
\hline AB & 2314.50 & 3 & 771.50 & 27.63 & $<0.0001$ \\
\hline Pure Error & 893.46 & 32 & 27.92 & & \\
\hline Cor Total & 9917.12 & 39 & & & \\
\hline
\end{tabular}

The TM values of the W-PA6G and W-PA6G-based composites were in the range of 709 to $1039 \mathrm{MPa}$ (Table 2). The interaction graph of TM is presented in Fig. $1 \mathrm{~b}$.
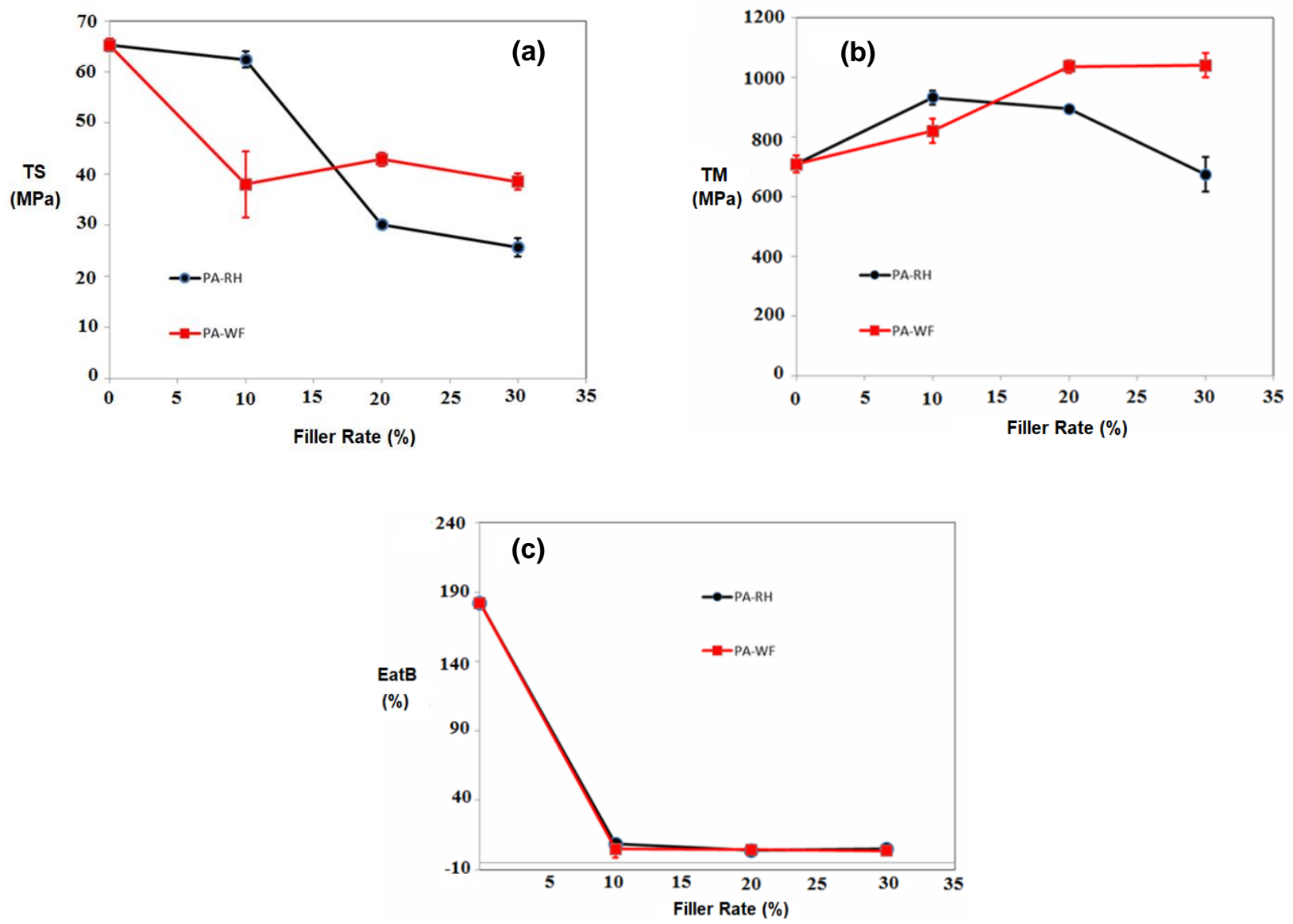

Fig. 1. Interaction graphs of tensile properties: (a): TS; (b): TM; and (c): EatB

The FT, FC, and their interaction (FTxFC) had a significant effect on TM (P < 0.0001). Initially, as expected, both RH and WF improved TM values of the composites. At higher filler contents, WF continued to improve TM values but surprisingly, over $10 \%$ 
utilization, $\mathrm{RH}$ addition significantly reduced the TM values. The $\mathrm{RH}$ is reported to be more thermal sensitive and has lower cellulose content compared to WF. It is believed that chemicals evaporating at high processing temperatures might cause chain scission of the polymer molecules. Improved TM values with lignocellulosic filler, in addition to the thermoplastic matrices, were also reported by other researchers (Klyosov 2007; Xu 2008; Mengeloglu and Karakuş 2012; Kiziltas et al. 2014; Yörür 2016; Çavuş 2020). It is explained that a mixture of high modulus filler and low modulus polymer results in a composite with higher modulus compared to the polymer itself (rule of mixture).

For EatB, values in the range of 3.6 to $182 \%$ were measured. The interaction graph of EatB is presented in Fig. 1c. Filler type did not have significant effect on EatB $(\mathrm{P}=$ 0.295). In contrast, filler content had a significant effect on EatB ( $\mathrm{P}<0.0001)$. Nuñez et al. (2003), La Mantia et al. (2005), and Dönmez Çavdar et al. (2011) stated that there is a decrease in elongation at break values due to increased brittleness of the resulting composites with the addition of lignocellulosic filler.

The interaction graphs of the flexural properties are presented in Fig. 2. Flexural strength values of W-PA6G and W-PA6G-based composites were in the range from 40.4 to $63.5 \mathrm{MPa}$ (Table 2 and Fig 2a). The statistical analysis showed that FT had a significant effect on FS (P = 0.045). The effects of FC and FTxFC interactions on FS were also statistically significant $(\mathrm{P}<0.0001)$. The WF filled W-PA6G composites provided overall better FS values than the RH filled ones. Because wood plastic composites are generally considered as an alternative to plastic lumber, it is useful to compare them with the ASTM D6662 (2007) polyolefin plastic lumber standard. According to this standard, flexural strength values are required to be at least $6.9 \mathrm{MPa}$. All manufactured composites provided results that were well over this standard.
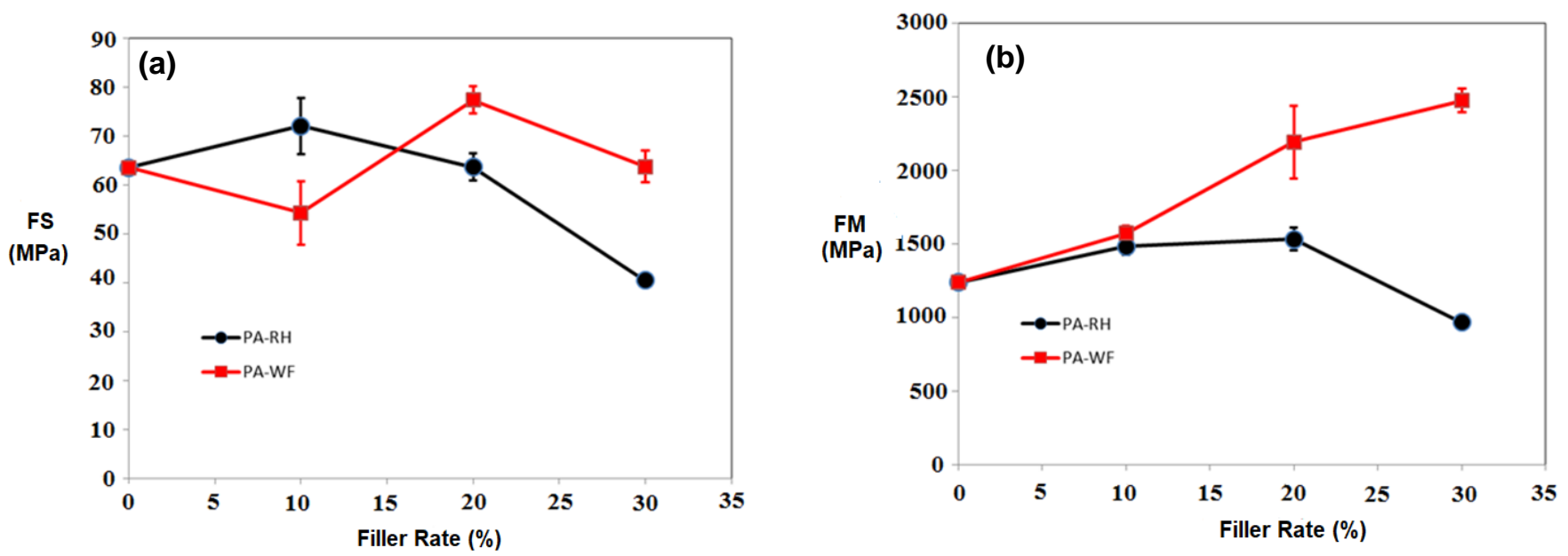

Fig. 2. Interaction graphs of flexural properties: (a): FS and (b) FM

The FM was significantly affected by FT, FC, and FTxFC interaction $(\mathrm{P}<0.0001)$. The FM values of W-PA6G and W-PA6G-based composites were in the range from 965 to $2472 \mathrm{MPa}$ (Table 2 and Fig 2b). The overall performance of WF was better than RH as fillers. Once again at higher filler contents, performance of composites filled with RH were remarkable reduced. The 30\% WF filled composites provided FM values of almost double of the W-PA6G. Kiziltas et al. (2014) reported an approximately 47\% increase in FM of PA6-based composites when $20 \%$ lignocellulosic material was used as filler. Jin and 
Matuana (2008) manufactured PVC-based composites using maple wood flour as lignocellulosic filler and reported an approximately $18.4 \%$ increase in FM of PVC-based composites when $20 \%$ lignocellulosic material was used as filler.

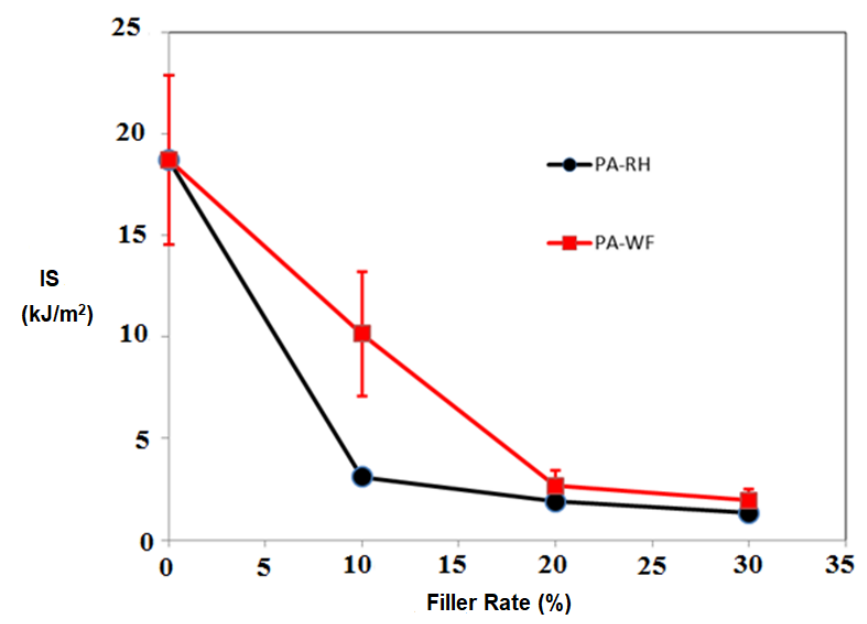

Fig. 3. Interaction graph of impact strength (IS)

For IS, values were measured in the range of 1.3 to $18.7 \mathrm{~kJ} / \mathrm{m}^{2}$. The interaction graph of IS was presented in Fig. 3. Filler type did not have a significant effect on IS (P = $0.174)$. In contrast, filler content had a significant effect on IS ( $P<0.0001)$. Regardless of filler type, IS values were significantly reduced with the rising percentage of filler. Addition of filler in the polymer matrix increased the brittleness of composite and limited their energy absorption potentials. Hajji et al. (2008) produced PVC composites using pine as lignocellulosic fillers. It was reported that the addition of filler reduced IS values. Reduced IS values with lignocellulosic filler presence was also reported by others (Liu et al. 2009; Çavdar et al. 2011; Kiziltas et al. 2014; Aydemir et al. 2015; Zierdt et al. 2015; Elsabbagh et al. 2017; Oliver-Ortega et al. 2018; Çavus 2020).

Morphology of the W-PA6G and W-PA6G-based composites (with 20\% filler) was studied using SEM. The SEM images of the selected samples are presented in Fig. 4. Nonhomogeneous distribution of the RH and WF fillers in W-PA6G matrix can be seen in Figs. $4 \mathrm{~b}$ and $4 \mathrm{c}$, respectively. At a certain part of the polymer matrix, fillers were grouped in close distance. This situation might cause to the heterogeneous mechanical properties based on the location samples.

\section{Thermal Properties}

Thermal properties are important characteristics for polymers and polymer composites. They play a key role in selecting processing parameters and final product application areas. In this study, DSC and TGA of W-PA6G and their 30\% RH and WF filled composites were evaluated. The DSC data of the studied samples are presented in Table 3. 


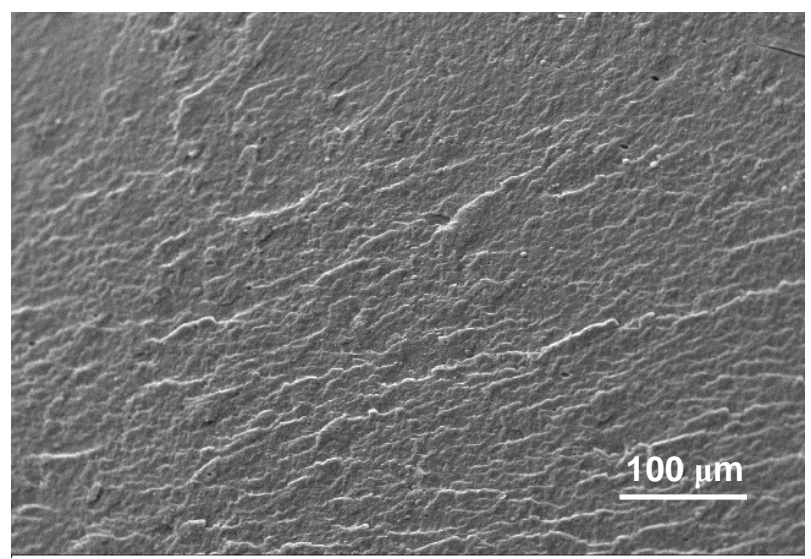

(a) W-PA6G

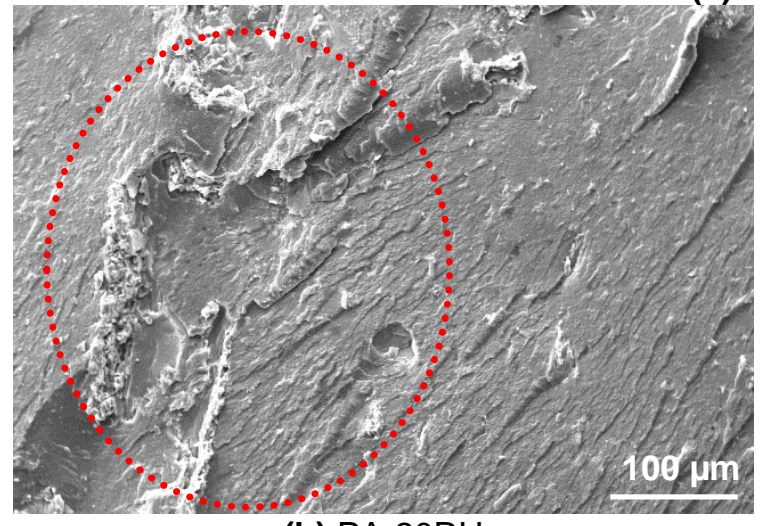

(b) $\mathrm{PA}-20 \mathrm{RH}$

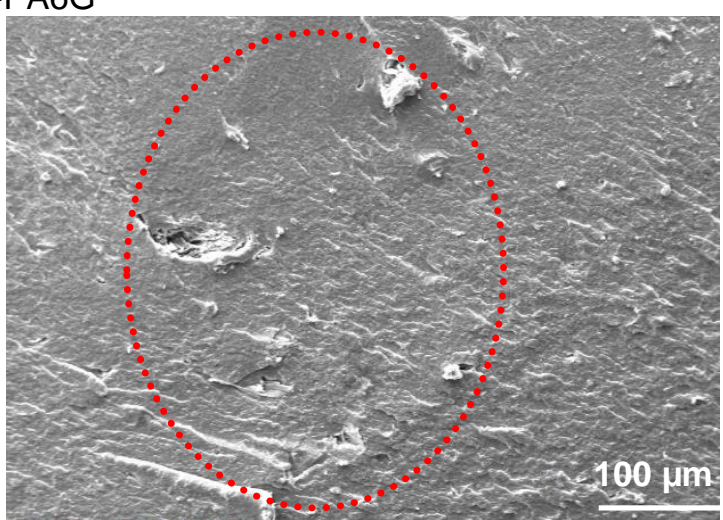

(c) PA-20WF

Fig. 4. SEM images of selected samples at $x 500$ magnification: (a) W-PA6G, (b) PA-20RH, and (c) PA-20WF

Table 3. DSC Data of Recycled W-PA6G-based WPCs

\begin{tabular}{|c|c|c|c|c|}
\hline ID & $\boldsymbol{T}_{\mathbf{m}}\left({ }^{\circ} \mathbf{C}\right)$ & $\boldsymbol{T}_{\mathbf{c}}\left({ }^{\circ} \mathbf{C}\right)$ & $\Delta \boldsymbol{H}(\mathbf{J} / \mathbf{g})$ & $\boldsymbol{X}_{\mathbf{c}}(\%)$ \\
\hline W-PA6G & 211.3 & 176.3 & 108.5 & 47.2 \\
\hline PA-30RH & 181.8 & $-^{\mathrm{a}}$ & 29.14 & 13.5 \\
\hline PA-30WF & 190.5 & $-^{\mathrm{a}}$ & 21.8 & 18.1 \\
\hline
\end{tabular}

a: Not detectable in DSC curves; $X_{c}$ : the crystallinity

Changes in the melting curve after lignocellulosic filler addition are presented in Fig. 5. The lignocellulosic filled composites had broader melting curves compared to the W-PA6G peak. Improved crystal growth provides a narrower peak (Xu et al. 2013), but restricting the formation of polymer crystals results in broader peaks (Ying et al. 2018). Results showed that the addition of both $\mathrm{RH}$ and WF lignocellulosic fillers in W-PA6G matrix reduced the melting temperatures $\left(T_{\mathrm{m}}\right)$ of W-PA6G from $211^{\circ} \mathrm{C}$ to $182{ }^{\circ} \mathrm{C}$ and 191 ${ }^{\circ} \mathrm{C}$ (Table 3). The crystallinity values of the PA30RH and PA-30WF composites (approximately 14\% and 18\%) were lower than the W-PA6G samples (approximately 47\%). Klata et al. (2003) reported that glass filament reinforcement reduced crystallinity of PA6 composites. Other researchers reported increased crystallinity in PP-based lignocellulosic composites due to nucleating ability of the lignocellulosic filler (Joseph et al. 2003; Arbelaiz et al. 2006; Lei and Wu 2010). Joseph et al. (2003) produced 
polypropylene-based composites with 10,20, and 30\% sisal fiber and observed an increase in crystallinity without changing $T_{\mathrm{m}}$. Similar findings were reported by Arbelaiz et al. (2006) for PP-based 30\% flax fiber composite (produced samples at crystallization temperature $\left(\mathrm{T}_{\mathrm{c}}\right)$ of $135^{\circ} \mathrm{C}$ and $140^{\circ} \mathrm{C}$ ). However, almost $9 \%$ lower crystallinity compared to PP ( $X_{\mathrm{cPP}}: 57.4 \%$ and $\left.X_{\mathrm{cPP}+\text { Flax: }}: 52.5 \%\right)$ was measured in composites produced with a $T_{\mathrm{c}}$ of $145^{\circ} \mathrm{C}$. It is obvious that material choice and composition, manufacturing parameters, and preferred manufacturing process might affect the crystallinity of the composites. There is a need for further study to investigate the effect of lignocellulosic fiber and their possible synergistic effect on the thermal properties of W-PA6G-based composites.

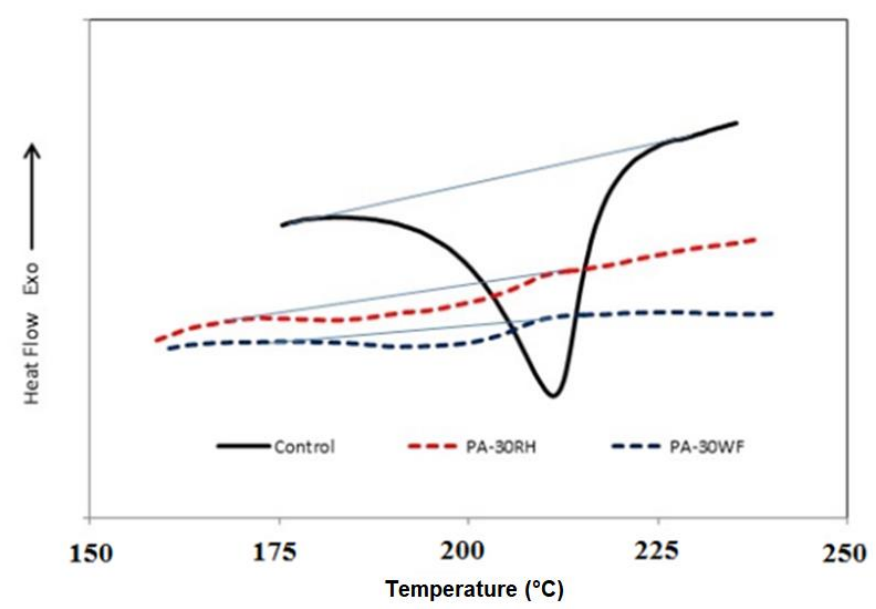

Fig. 5. DSC melting curves of the samples

Thermogravimetric analysis is one of the key thermal analysis techniques to investigate the thermal behavior of carbonaceous materials. It measures the rate of weight loss of the sample as a function of temperature and time, which is utilized to predict the thermal behavior of the material (Mansaray and Ghaly 1998). The TGA and DTGA (derivative thermogravimetric analysis) curves and TGA data of the samples are presented in Figs. 6a and 6b, and Table 4, respectively. The TGA of both RH and WF revealed an initial slight weight loss between ambient temperature and approximately $100{ }^{\circ} \mathrm{C}$. This could be due to the gradual evaporation of absorbed moisture. The onset, endset, and major decomposition temperatures of the $\mathrm{RH}$ were 173,493 , and $329{ }^{\circ} \mathrm{C}$, respectively. The temperatures for the WF were 182,461 , and $356{ }^{\circ} \mathrm{C}$. This mass loss was due to the decomposition of the three major constituents of the lignocellulosic fillers (cellulose, hemicellulose, and lignin). Hemicellulose, cellulose, and lignin decomposes in the range of 150 to $350{ }^{\circ} \mathrm{C}, 275$ to $350{ }^{\circ} \mathrm{C}$, and 250 to $500{ }^{\circ} \mathrm{C}$, respectively (Mansaray and Ghaly 1998; Kim et. al 2004). At $750{ }^{\circ} \mathrm{C}$, the ash content of RHF (39\%) was much higher than that of WF (18.9\%). Ash in the RHF is mainly composed of silica (96\%) (Kim et al. 2004). The mass loss steps of W-PA6G occurred rapidly above $400{ }^{\circ} \mathrm{C}$. Its mass loss started at around $296{ }^{\circ} \mathrm{C}$ and was completed at $466{ }^{\circ} \mathrm{C}$ with the maximum degradation rate temperature at $432{ }^{\circ} \mathrm{C}(\mathrm{Fig} 8 \mathrm{~b})$. A similar result for PA6 was reported by Elsabbagh et al. (2017). The results showed that the thermal stability of RHF and WF was lower than that of W-PA6G. 
(a)

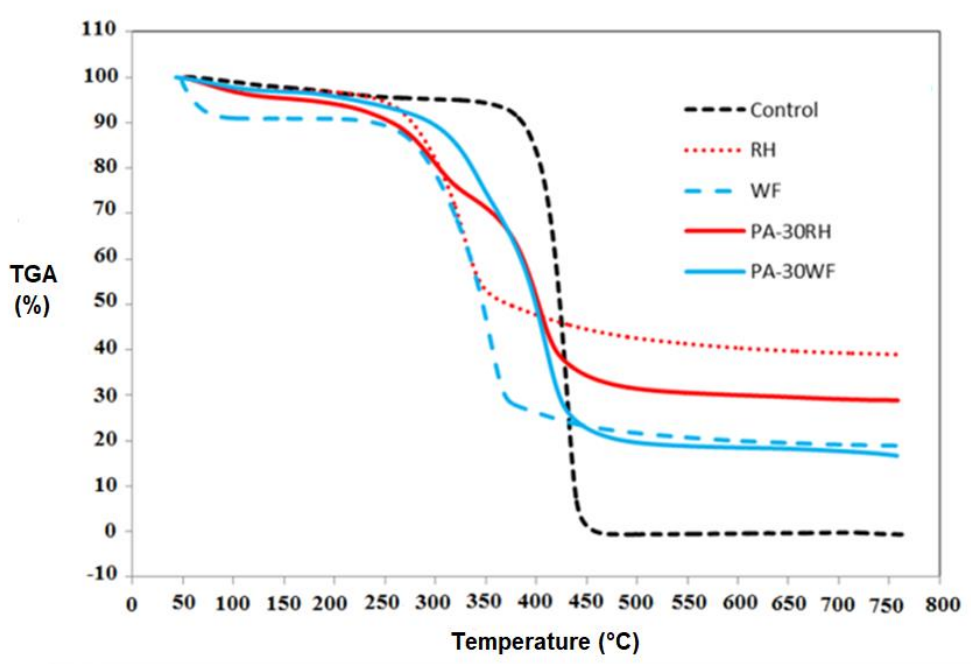

(b)

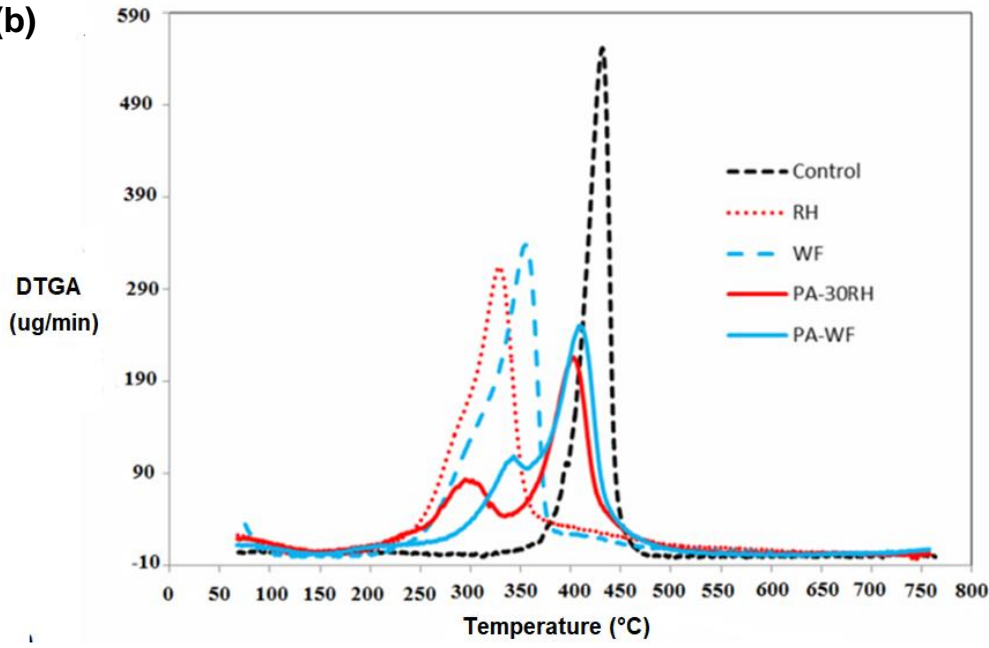

Fig. 6. (a) TGA mass loss and (b) derivative DTGA curves of the samples

Table 4. TGA Data of Recycled W-PA6G-based WPCs

\begin{tabular}{|c|c|c|c|c|c|c|}
\hline \multicolumn{2}{|c|}{ ID } & Tonset $\left({ }^{\circ} \mathrm{C}\right)$ & $\begin{array}{c}T_{\text {endset }} \\
\left({ }^{\circ} \mathbf{C}\right)\end{array}$ & $\begin{array}{c}T_{\text {decomp }} \\
\left({ }^{\circ} \mathrm{C}\right)\end{array}$ & $\begin{array}{c}\text { Weight Loss at } \\
T_{\text {onset }}-T_{\text {endset }} \\
\text { (\%) }\end{array}$ & $\begin{array}{c}\text { Residue at } 750 \\
{ }^{\circ} \mathrm{C}(\%)\end{array}$ \\
\hline \multicolumn{2}{|c|}{ W-PA6G } & 296.4 & 465.6 & 431.6 & 95.2 & - \\
\hline \multirow{2}{*}{$\begin{array}{l}\text { PA- } \\
30 R H\end{array}$} & $\begin{array}{c}1^{\text {st }} \\
\text { Peak }\end{array}$ & 171.7 & 327.6 & 295.0 & 21.8 & \multirow{2}{*}{28.9} \\
\hline & $\begin{array}{c}2^{\text {nd }} \\
\text { Peak }\end{array}$ & 327.6 & 492.0 & 404.0 & 43.1 & \\
\hline \multirow{2}{*}{$\begin{array}{l}\text { PA- } \\
\text { 30WF }\end{array}$} & $\begin{array}{c}1^{\text {st }} \\
\text { Peak }\end{array}$ & 204.9 & 348.8 & 338.6 & 20.4 & \multirow{2}{*}{16.9} \\
\hline & $\begin{array}{c}2^{\text {nd }} \\
\text { Peak }\end{array}$ & 348.8 & 447.5 & 406.9 & 52.1 & \\
\hline \multicolumn{2}{|c|}{$\mathrm{RH}$} & 172.8 & 492.7 & 328.6 & 54.2 & 39.0 \\
\hline \multicolumn{2}{|c|}{ WF } & 182.3 & 461.0 & 355.6 & 68.2 & 18.9 \\
\hline
\end{tabular}


In the RH and WF filled W-PA6G composites, two distinct DTGA peaks were detected. Through the addition of $\mathrm{RH}$ and WF, it was found that the onset temperature for degradation decreased to $172{ }^{\circ} \mathrm{C}$ and $182{ }^{\circ} \mathrm{C}$, respectively. This decrease is related to the thermal degradation of hemicelluloses followed by alpha cellulose and finally by lignin (Elsabbagh et al. 2017). The onset-endset temperatures of the second decomposition peaks of RH and WF filled composites were 328 to $492{ }^{\circ} \mathrm{C}$ and 348 to $447{ }^{\circ} \mathrm{C}$, respectively. Residue amounts at $750{ }^{\circ} \mathrm{C}$ for RH and WF filled composites were around $29 \%$ and $17 \%$, respectively.

\section{CONCLUSIONS}

In this study, the effect of filler type (FT) and filler content (FC) on the mechanical, morphological, and thermal properties of waste-casting polyamide 6 (W-PA6G)-based composites were investigated. During manufacturing, N-butyl benzene sulfonamide (NBBSA) and $\mathrm{LiCl}$ were utilized as a plasticizer and as melt temperature-lowering salts. The following conclusions were derived:

1. The rice husk (RH) and wood fiber (WF) filled W-PA6G-based composites were successfully manufactured using a combination of extrusion and injection molding.

2. The WF filled W-PA6G-based composites provided better tensile and flexural properties (both strength and modulus) than the RH filled ones at $20 \%$ and $30 \%$ filler contents. Impact strength values with lignocellulosic filler presence reduced.

3. Lignocellulosic filler presence resulted in reduced melting temperature and crystallinity of the W-PA6G-based composites. This reduction was more pronounced in the RH filled ones.

\section{ACKNOWLEDGMENTS}

The authors would like to thank The Scientific and Technological Research Council of Turkey (TÜBİTAK) for providing Research Grant (Project No. 119O615) that made this research possible.

\section{REFERENCES CITED}

Adhikary, K. B., Pang, S. S., and Staiger, M. P. (2008). "Dimensional stability and mechanical behaviour of wood-plastic composites based on recycled and virgin highdensity polyethylene (HDPE)," Composites Part B: Engineering 39(5), 807-915. DOI: 10.1016/j.compositesb.2007.10.005

Amintowlieh, Y., Sardashti, A., and Simon, L. C. (2012). "Polyamide 6-wheat straw composites: Effects of additives on physical and mechanical properties of the composite," Polymer Composites 33(6), 976-984. DOI: 10.1002/pc.22228

Arbelaiz, A., Fernández, B., Ramos, J. A., and Mondragon, I. (2006). "Thermal and crystallization studies of short flax fibre reinforced polypropylene matrix composites: 
Effect of treatments," Thermochimica Acta 440(2). 111-121. DOI:

10.1016/j.tca.2005.10.016

ASTM D256 (2000). "Standard test methods for impact resistance of plastics and electrical insulating materials," ASTM International, West Conshohocken, PA, USA.

ASTM D638-03 (2001). "Standard test method for tensile properties of plastics," ASTM International, West Conshohocken, PA, USA.

ASTM D790-03 (2003). "Standard test methods for flexural properties of unreinforced and reinforced plastics and electrical insulating materials," ASTM International, West Conshohocken, PA, USA.

ASTM D6662 (2007). "Standard specification for polyolefin-based plastic lumber decking boards," ASTM International, West Conshohocken, PA, USA.

Aydemir, D., Kiziltas, A., Kiziltas, E. E., Gardner, D. J., and Gunduz, G. (2015). "Heat treated wood-nylon 6 composite," Composites Part B: Engineering 68, 414-423. DOI: 10.1016/j.compositesb.2014.08.040

Bozdemir, M. (2011). "The effect of water absorption in cast PA6G material on processing parameters," Scientific Research and Essays 6(4), 714-719. DOI: 10.5897/SRE10.411

Çavdar, D. A., Kalaycioğlu, H., and Mengeloğlu, F. (2011). "Tea mill waste fibers filled thermoplastic composites: The effects of plastic type and fiber loading," Journal of Reinforced Plastics and Composites 30(10), 833-844. DOI: 10.1177/0731684411408752

Çavdar, D. A., Torun, S. B., Ertas, M., and Mengeloğlu, F. (2019). “Ammonium zeolite and ammonium phosphate applied as fire retardants for microcrystalline cellulose filled thermoplastic composites," Fire Safety Journal 107, 202-209.

DOI: 10.1016/j.firesaf.2018.11.008

Çavus, V. (2020). "Selected properties of mahogany wood flour filled polypropylene composites: The effect of maleic anhydride-grafted polypropylene (MAPP)," BioResources 15(2), 2227-2236. DOI: 10.15376/biores.15.2.2227-2236

Chen, J., and Gardner, D. J. (2008). "Dynamic mechanical properties of extruded nylonwood composites," Polymer Composites 29(4), 372-379. DOI: 10.1002/pc.20400

Elsabbagh, A., Steuernagel, L., and Ring, J. (2017). "Natural fibre/PA6 composites with flame retardance properties: Extrusion and characterization," Composites Part B: Engineering 108, 325-333. DOI: 10.1016/j.compositesb.2016.10.012

Espert, A., Vilaplana, F., and Karlsson, S. (2004). "Comparison of water absorption in natural cellulosic fibres from wood and one-year crops in polypropylene composites and its influence on their mechanical properties," Composites Part A: Applied Science and Manufacturing 35(11), 1267-1276. DOI: 10.1016/j.compositesa.2004.04.004

Formisano, B. R., and Bonten, C. (2019). "Recycling of cast polyamide 6 using a lubricant," AIP Conference Proceedings 2055(1), Article ID 020001. DOI: $10.1063 / 1.5084802$

Formisano, B., Göttermann, S., and Bonten, C. (2016). "Recycling of cast polyamide waste on a twin-screw-extruder," AIP Conference Proceedings 1779(1), Article ID 140002. DOI: $10.1063 / 1.4965582$

Gardner, D. J., Han, Y., and Wang, L. (2015). "Wood-plastic composite technology," Current Forestry Reports 1, 139-150. DOI: 10.1007/s40725-015-0016-6

Hajji, P., Marchand, F., and Pirri, R. (2008). "Wood-PVC composites: formulation optimisation," Plastics, Rubber and Composites 37(9-10), 388-391. DOI: 10.1179/174328908X356527 
Jiang, H. H, and Kamdem, D. P. (2004). "Development of poly(vinyl chloride)/wood composites. A literature review," Journal of Vinyl and Additive Technology 10(2), 5969. DOI: $10.1002 / \mathrm{vnl} .20009$

Jin, S., and Matuana, L. M. (2008). "Coextruded PVC/wood-flour composites with WPC cap layers," Journal of Vinyl and Additive Technology 14(4), 197-203. DOI: 10.1002/vnl.20162

Joseph, P. V., Joseph, K., Thomas, S., Pillai, C. K. S., Prasad, V. S., Groeninckx, G., and Sarkissova, M. (2003). "The thermal and crystallisation studies of short sisal fibre reinforced polypropylene composites," Composites Part A: Applied Science and Manufacturing 34(3), 253-266. DOI: 10.1016/S1359-835X(02)00185-9

Kabakci, A., and Kesik, H. I. (2020). "The effect of water-based insulation paint to laminate flooring panels on the thermal conductivity coefficient and adhesion resistance," BioResources 15(3), 6110-6122. DOI: 10.15376/biores.15.3.6110.6122

Kim, H. S., Yang, H. S., Kim, H. J., and Park, H. J. (2004). "Thermogravimetric analysis of rice husk flour filled thermoplastic polymer composites," Journal of Thermal Analysis and Calorimetry 76(2), 395-404. DOI: 10.1023/B:JTAN.0000028020.02657.9b

Kiziltas, A., Gardner, D. J., Han, Y., and Yang, H. S. (2014). "Mechanical properties of microcrystalline cellulose (MCC) filled engineering thermoplastic composites," J. of Polymers and the Environment 22(3), 365-372. DOI: 10.1007/s10924-014-0676-5

Klata, E., Van de Velde, K., and Krucińska, I. (2003). "DSC investigations of polyamide 6 in hybrid GF/PA 6 yarns and composites," Polymer Testing 22(8), 929-937. DOI: 10.1016/S0142-9418(03)00043-6

Klyosov, A. A. (2007). Wood-plastic Composites, $1^{\text {st }}$ Ed., Wiley Interscience, Hoboken, NJ, USA.

Ku, H., Wang, H., Pattarachaiyakoop, N., and Trada, M. (2011). "A review on the tensile properties of natural fiber reinforced polymer composites," Composites Part B: Engineering 42(4), 856-873. DOI: 10.1016/j.compositesb.2011.01.010

La Mantia, F. P., Morreale, M., and Izhak, Z. A. M. (2005). "Processing and mechanical properties of organic filler-polypropylene composites," Journal of Applied Polymer Science 96, 1906-1913. DOI: 10.1002/app.21623

Lei, Y., and Wu, Q. (2010). "Wood plastic composites based on microfibrillar blends of high density polyethylene/poly(ethylene terephthalate)," Bioresource Technology 101(10), 3665-3671. DOI: 10.1016/j.biortech.2009.12.069

Liu, H., Wu, Q., and Zhang, Q. (2009). "Preparation and properties of banana fiberreinforced composites based on high density polyethylene (HDPE)/Nylon-6 blends," Bioresource Technology 100(23), 6088-6097. DOI: 10.1016/j.biortech.2009.05.076

Mansaray, K. G., and Ghaly, A. E. (1998). "Thermal degradation of rice husks in nitrogen atmosphere," Bioresource Technology 65(1-2), 13-20. DOI: 10.1016/S09608524(98)00031-5

Malkapuram, R., Kumar, V., and Negi, Y. S. (2009). "Recent development in natural fiber reinforced polypropylene composites," Journal of Reinforced Plastics and Composites 28(10), 1169-1189. DOI: 10.1177/0731684407087759

Mengeloglu, F., and Karakuş, K. (2012). "Mechanical properties of injection-molded foamed wheat straw filled HDPE biocomposites: The effects of filler loading and coupling agent contents," BioResources 7(3), 3293-3305.

Mengeloglu, F., Kurt, R., Gardner, D. J., and O'Neill, S. (2007). "Mechanical properties of extruded high density polyethylene and polypropylene wood flour decking boards," Iranian Polymer Journal 16(7), 477-487. 
Nuñez, A. J., Sturn, P. C., Kenny, J. M., Aranguren, M. I., Marcovich, N. E., and Reboredo, M. M. (2003). "Mechanical characterization of polypropylene-wood flour composites," Journal Applied Polymer Science 88(6), 1420-1428. DOI: 10.1002/app.11738

Oliver-Ortega, H., Méndez, J. A., Espinach, F. X., Tarrés, Q., Ardanuy, M., and Mutjé, P. (2018). "Impact strength and water uptake behaviors of fully bio-based PA11-SGW composites," Polymers 10(7), Article number 717. DOI: 10.3390/polym10070717

Poletto, M., Dettenborn, J., Zeni, M., and Zattera, A. J. (2011). "Characterization of composites based on expanded polystyrene wastes and wood flour," Waste Management 31(4), 779-784. DOI: 10.1016/j.wasman.2010.10.027

Sears, K. D., Jacobson, R., Caulfield, D. F., and Underwood, J. (2001). "Reinforcement of engineering thermoplastics with high purity wood cellulose fibers," in: Proceedings of the $6^{\text {th }}$ International Conference on Wood-Plastic Composites, Forest Products Society, Madison, WI, USA, pp. 27-34.

Ying, J., Wang, W., Peng, X., Qiu, Z., Ma, X., Zhang, S., and Wang, J. (2018). "Preparation of monomer casting nylon-6- $b$-polydimethylsiloxane copolymers with enhanced mechanical and surface properties," Polymer-Plastics Technology and Engineering 57(16), 1634-1641. DOI: 10.1080/03602559.2017.1410846

Xu, S., Sun, L., He, J., Han, H., Wang, H., Fang, Y., and Wang, Q. (2018). "Effects of $\mathrm{LiCl}$ on crystallization, thermal, and mechanical properties of polyamide 6/wood fiber composites," Polymer Composites, 39(S3), E1574-E1580. DOI: 10.1002/pc.24507

$\mathrm{Xu}, \mathrm{S}$., Zhao, X., and Ye, L. (2013). "Mechanical and crystalline properties of monomer casting nylon-6/SiO2 composites prepared via in situ polymerization," Polymer Engineering \& Science 53(9), 1809-1822. DOI: 10.1002/pen.23449

Xu, X. (2008). Cellulose Fiber Reinforced Nylon 6 or Nylon 66 Composites, Ph.D. Dissertation, Georgia Institute of Technology, Atlanta, GA, USA.

Yörür, H. (2016). "Utilization of waste polyethylene and its effects on physical and mechanical properties of oriented strand board," BioResources 11(1), 2483-2491. DOI: 10.15376/biores.11.1.2483-2491

Yörür, H., Esen, R., and Yapici, F. (2013). "The determination of thickness swelling of oriented strand board (OSB) manufactured from scots pine by using cast-polyamide," Pro Ligno 9(4), 536-539.

Yörür, H., and Şeker, B. (2019). "Physical and thermal propertıes of recycled cast polyamide 6 additive wood plastic composites," in: Proceedings of the 29th International Conference Research for Furniture Industry, Ankara, Turkey, pp. 457-462

Zierdt, P., Mitzner, E., Gomoll, A., Theumer, T., and Lieske, A. (2016). "Synthesis of polyamide 6/11 copolymers and their use as matrix polymer in wood-plastic composites," Journal of Applied Polymer Science 133(46), Article ID 44155. DOI: 10.1002/APP.44155

Zierdt, P., Theumer, T., Kulkarni, G., Däumlich, V., Klehm, J., Hirsch, U., and Weber, A. (2015). "Sustainable wood-plastic composites from bio-based polyamide 11 and chemically modified beech fibers," Sustainable Materials and Technologies 6, 6-14. DOI: $10.1016 /$ j.susmat.2015.10.001

Article submitted: August 20, 2020; Peer review completed: October 25, 2020; Revised version received and accepted: November 25, 2020; Published: December 4, 2020.

DOI: 10.15376/biores.16.1.655-668 